\title{
Displaying medication costs on dispensing labels as a strategy to reduce wastage: views of the Welsh general public
}

This article was published in the following Dove Press journal:

Integrated Pharmacy Research and Practice

24 October 2017

Number of times this article has been viewed

\section{Rowan Yemm \\ Christabel Jones \\ Tryphosa Mitoko}

Cardiff University School of Pharmacy and Pharmaceutical Sciences, Cardiff University, Cardiff, Wales, UK
Correspondence: Rowan Yemm Cardiff University School of Pharmacy and Pharmaceutical Sciences, Cardiff University, Redwood Building, King Edward VII Avenue, Cardiff CFI0 9NB, Wales, UK

Tel +442920874538

Email YemmR@cardiff.ac.uk
Introduction: In 2015, the UK health secretary made public an intention to include the value of medicines costing over $£ 20$ on dispensing labels as an attempt to reduce wastage attributable to patient behavior. However, there is a lack of evidence investigating the potential effect or feasibility of this proposal, and concerns have been raised that it may introduce new problems in vulnerable groups. This pilot study aimed to gather views of the Welsh general public on this subject.

Methods: Six focus groups from within key population groups were conducted. A snowball sampling strategy was employed with participants recruited via a neutral gatekeeper. Focus groups session were audio recorded and transcribed verbatim and iterative thematic analysis was used to identify emergent themes.

Results: Six focus groups were conducted. Three key themes were identified: "influence of cost" - whereby participants expressed concern about cost linking to their perceived value, guilt for needing prescribed medication and irrelevance of cost if the medication was considered necessary; "knowledge is power" - whereby participants expressed a desire to know more about their medicines and engage with health care professionals about them, and felt information on dispensing labels alone would be insufficient to support this and "blame the system" - whereby participants felt responsibility for wastage should be shared by both system and patient and identified existing wasteful practices such as inappropriate prescribing, ordering and disposal of returned medicines.

Conclusion: Findings were largely consistent with criticisms publicized by professional bodies that introducing cost may serve to make patients feel guilty or unworthy rather than encourage them to use their medicines appropriately. Similarly, providing cost information on labels alone was considered insufficient and therefore additional counseling or education would be necessary to prevent misunderstanding. The acknowledgment of system factors contributing to wastage highlights an important role for pharmacists to become involved in using medicines more cost-effectively. However, cost was considered irrelevant if the medicine was deemed necessary by the patient, and therefore more mindful prescribing of superfluous items should be promoted.

Keywords: medicines wastage, cost, adherence, patient perspectives

\section{Introduction}

In early 2017, the British Medical Association described the UK's National Health Service (NHS) as being at breaking point. ${ }^{1}$ Wastage of medicines, defined as medicines given to the patient but not consumed, ${ }^{2}$ is believed to contribute heavily to avoidable NHS costs. It is estimated that $£ 300$ million worth of medication is discarded in England 
annually, of which half could potentially be avoided, ${ }^{3}$ making this a topical issue in both medical and political arenas.

Of the existing strategies adopted to reduce medicines wastage, Medicines Usage Reviews (MURs), 28-day prescribing and awareness campaigns, have proven to be most successful. ${ }^{2}$ However, as strategies have often been adopted in tandem, it is difficult to assess their individual successes, and not all initiatives have proven cost-effective. ${ }^{2}$ Indeed, it has been acknowledged instead that a "one-size-fits-all approach" is not appropriate for tackling a complex issue such as wastage. ${ }^{3}$

UK patients are largely unaware of the cost of their medicines, as they are either provided free of charge (Northern Ireland, Wales or where exemption criteria apply) or subject to a standard prescription charge (currently £8.60). Informing patients of the cost of their medicines through inclusion of the price on the dispensing label has, over recent years, been sporadically proposed as a novel strategy to encourage patients to reconsider wasting their medicines.

However, the literature is not necessarily supportive of this proposal. In a report carried out in 2010 by York Health Economics Consortium, an expert panel of health care professionals and medicine users discussed the inclusion of cost on prescription medicines as a strategy for reducing wastage. While it was felt useful to make patients more aware of the cost of medicines, most medicine users believed that the inclusion of costs on labels might possibly deter some patients from taking essential treatment, reducing adherence and increasing the risk of adverse events. ${ }^{3}$

Following this report, the Department of Health held a roundtable event in 2011 with representatives from patients, health care professionals, the NHS and the pharmaceutical industry to discuss the findings and identify ways to reduce medicines wastage. The inclusion of indicative prices on medicine labels was again discussed, but did not receive support as concerns were raised that more vulnerable patient groups, such as the elderly, might be deterred from taking their medications if they believed they were burdening the NHS financially. ${ }^{4}$ Based on these conclusions, the 2012 government strategy to reduce wastage recommended that this proposal should not be pursued further. ${ }^{5}$

However, despite lack of support or existing evidence to indicate effectiveness, in July 2015, the Health Secretary Jeremy Hunt unveiled a plan to include the cost of medicines costing more than $£ 20$ on the dispensing labels, followed by the words "funded by the UK taxpayer." ${ }^{\text {He claimed that }}$ publishing the cost would increase patient responsibility and decrease financial strain on the NHS. Response to this has been largely negative. The Royal Pharmaceutical Society acknowledged that cost may be a factor contributing to patient adherence, but as medicines wastage is a multifaceted issue, it stated it would require a more complex approach to address. ${ }^{7}$ The Patients' Association expressed concern that patients would feel like they are being rationed or a financial burden to society at a time when instilling public confidence in the NHS is necessary. ${ }^{8}$ The General Pharmaceutical Council advised potential negative consequences needed to be considered and advised piloting and testing before implementation. ${ }^{9}$

The lack of published evidence supporting the policy, as well as practical issues for the introduction of a practice change, might make the proposal more of a hindrance in the future. ${ }^{10}$ To our knowledge, no evidence currently exists in the literature which has piloted this proposal or assessed the effectiveness or impact of knowing the medication cost on patient behavior. The lack of evidence to support this proposal highlights the need for research into its potential impact on patient behavior contributing to medicines wastage.

\section{Aims and objectives}

This study aimed to explore how making patients aware of the cost of their medicines might impact on their behavior and medicines usage. The primary objective was therefore to explore the views of members of the general public on including the NHS cost of prescribed medicines on the dispensing label. A secondary objective was to identify key themes to inform a national questionnaire to be sent to a wider population on this subject.

\section{Methodology \\ Ethical approval}

The Cardiff School of Pharmacy and Pharmaceutical Sciences Research and Ethics Committee granted ethical approval for this study on October 23, 2015.

\section{Data collection strategy}

A qualitative data collection approach was adopted to allow for in-depth analysis of people's feelings and attitudes. Focus groups were selected because they allow participants to interact with each other to generate new concepts.

\section{Sample}

When selecting participants, it was important to consider how the proposal might be received across different population groups. Three population groups (students, working age adults and senior citizens) were targeted which were likely to represent a range of age, educational backgrounds, ethnicities 
and socioeconomic groups and would additionally be likely to include people who either are or have been exposed to others, regularly taking medicines for longer-term health conditions. By separating groups according to these characteristics, the aim was to make participants feel as comfortable as possible in expressing their views and also to enable comparisons to be drawn between groups during analysis.

\section{Recruitment}

Data were collected in October and November 2015. A purposive snowball sampling technique was adopted by contacting a representative of the population group, who then passed in the study recruitment information onto others. Potential group representatives were contacted via email through a neutral gatekeeper (a university staff member). A covering letter briefly explaining the study, a participant information sheet detailing the study aims and process, and a consent form were attached to each email. Participants were required to provide written consent by signing the consent form before taking part in the study, and were informed that their consent could be withdrawn at any time.

\section{Sample size estimation and data saturation}

Data saturation is reached when analysis produces no new emergent themes. As this research had a specific question, it was expected that six focus groups would be sufficient to provide enough data to answer research questions. This was assessed by iterative comparison of emergent themes after each focus group was transcribed. The intention was to recruit 6-12 members per group. ${ }^{11}$

\section{Focus group format}

The participants in each focus group were encouraged to discuss their opinions concerning the cost of medicines, medicines wastage and their reaction to the proposal to include the medication cost on the label of a dispensed medication box. Two researchers independently reviewed the literature and composed questions and topic areas for the focus group discussions. These were then reviewed and discussed with the research team, and a collective topic guide was composed. The structure of the questions in the guide was semi-structured not only to allow flexibility of discussion but also to keep the conversation relevant to the study's aims. Broad, open questions were used to initiate topics and probing questions, if necessary, to steer conversation or to focus discussions. When addressing participants' reaction to the proposal to include cost on the label, a selection of labeled medication boxes was used as props to facilitate discussion, some of which included the cost. Some sample questions are shown in Table 1.

\section{Analysis}

The focus groups were recorded using a digital electronic voice recording device. Audio recordings were transcribed verbatim, and the transcripts were analyzed to identify emergent themes. The widely adopted principles of thematic analysis $^{12}$ were used to derive meaningful patterns within the data. Two researchers (CJ and TM) independently conducted coding and analysis of the data to generate themes. All interpretations made from the data were then reviewed and discussed together with the research team to confirm all valid themes had been recognized and to further refine themes where necessary. Any disagreements or differences in interpretation were discussed as a team and compromise reached by referring back to the original transcripts.

\section{Data processing and confidentiality}

All data collected was processed and stored anonymously with all identifying information relating to participants removed. For the purpose of the study, participants were allocated a unique study reference number, which was used for the duration of the study. To ensure the study was trustworthy, Lincoln and Guba's ${ }^{13}$ evaluative criteria were taken into consideration throughout.

Table I Sample questions from final topic guide

\begin{tabular}{lll}
\hline Subject area & Broad questions & Probing questions \\
\hline Awareness of cost & Can you tell me anything different you notice & Does the cost surprise you? Why/not? What do you understand \\
& about these boxes of medicines? & by the term "cost to NHS"? \\
& How do you feel about the cost being displayed? & Does it interest you to know the cost? Why/not? \\
Interpretation of cost & What do you think it means if a medicine is & Does it change your opinion of the medicine? \\
& expensive? & Would it make you more likely to take the medicine? \\
& What might you do differently knowing the cost & Would it encourage you to discuss cost with your GPI \\
& of your medicine? & pharmacist/other? \\
\hline
\end{tabular}

Abbreviations: GP, general practitioner; NHS, National Health Service. 


\section{Results}

A total of 34 participants took part in six focus groups. No person who was approached to participate refused to take part. The demographics of each group are summarized in Table 2. Each focus group lasted between 1 and 1.5 hours.

Table 3 shows key quotations from participants arranged by theme.

\section{Theme I: influence of cost}

There was a general consensus across groups that if a medicine is deemed "necessary," whether by the patient or their prescriber, or because of the condition it is being used for, then it should be taken irrespective of the cost (Table 3, quote A). In these instances, participants argued that telling patients the cost of their medicines would only serve to make them feel guilty about needing it (Table 3, quote B).

Participants in the elderly groups in particular felt that their general practitioners (GPs) always prescribe the cheapest available medication, and there was a consensus among participants that cheaper medicines are generally less effective (Table 3, quotes $\mathrm{C}$ and D). This belief was largely based on their own experiences of having started on one medication and then being changed on to another because it was found to be unsuitable or ineffective. Participants across the groups felt that being told they were taking a lower-cost medication might make them feel short-changed or devalued (Table 3, quotes $\mathrm{E}$ and $\mathrm{F}$ ). In addition, participants felt some patients may believe the value of their medication is linked to their

Table 2 Focus group demographics

\begin{tabular}{llll}
\hline Focus group & Participants $(\mathbf{n})$ & Male, $\%(\mathbf{n})$ & Demographics \\
\hline 1 & 5 & $20(\mathrm{I})$ & Senior citizens aged over 65 years \\
2 & 5 & $20(\mathrm{I})$ & Senior citizens aged over 65 years \\
3 & 6 & $17(\mathrm{I})$ & Senior citizens aged over 65 years \\
4 & 7 & $57(4)$ & Non-pharmacy and pharmacy university staff and postgraduate students \\
5 & 6 & $33(2)$ & Non-pharmacy students, aged I8-23 years \\
6 & 5 & $20(\mathrm{I})$ & Non-pharmacy students, aged I8-23 years \\
\hline
\end{tabular}

Table 3 Key quotations displayed by theme

\begin{tabular}{|c|c|c|}
\hline Theme I: Influence of cost & Theme 2: Knowledge is power & Theme 3: Blame the system, not me! \\
\hline $\begin{array}{l}\text { A “When they're keeping you alive then you're } \\
\text { going to take them aren't you, whatever the cost!" } \\
\text { E2P2 } \\
\text { B “There's no point in blackmailing me about the } \\
\text { cost if that's what my professional says is what l've } \\
\text { got to take" E2P5 } \\
\text { C "Some people would demand the dearer ones } \\
\text { because they think it would do them better" E2P3 } \\
\text { D “You would assume that because one is more } \\
\text { expensive that it would work better, wouldn't you? } \\
\text { If it's more expensive then it must be a better } \\
\text { product" SP3 } \\
\text { E 'If you start telling a patient on a regular basis } \\
\text { 'do you know how much this costs', that there is a } \\
\text { real risk that that patient feels... that they are not } \\
\text { worth that drug” AP7 } \\
\text { F "As you start to bring cost in there is a } \\
\text { perception by patient... that you don't care about } \\
\text { them and you're just trying to give them something } \\
\text { cheap” API } \\
\text { G “The reasons you would not take a medicine is } \\
\text { either because you forget - and knowing the cost } \\
\text { won't make your memory better - or because you } \\
\text { don't need it anymore” AP2 }\end{array}$ & $\begin{array}{l}\mathrm{H} \text { 'It's about putting things into context for the } \\
\text { patient and the patient understanding exactly the } \\
\text { benefits of what they're taking and having that } \\
\text { really good patient-centred conversation" SP3 } \\
\text { I 'If you're going to have a proper discussion } \\
\text { about [wastage] it should be via a conversation, } \\
\text { not via sticking something on a label” AP3 } \\
\text { J "The more direct the link with a positive effect, } \\
\text { the less problem of wastage there would be, and } \\
\text { that comes down to education" API } \\
\text { K "The price I think is interesting for people to see } \\
\text { how much they are costing the health service or } \\
\text { how much they're getting back of their tax" EIP3 } \\
\mathrm{L} \text { “I'd like to be informed and think 'yes I am on } \\
\text { an expensive item for the surgery' but they're } \\
\text { willing to keep me going, especially when it oil } \\
\text { adds up" EIP2 } \\
\text { M 'If you force thinking about cost in that way } \\
\text { the end result is that you undermine the patient's } \\
\text { confidence in the integrity of their medical } \\
\text { practitioners" AP4 }\end{array}$ & $\begin{array}{l}\mathrm{N} \text { "They're free so they order them even if they don't } \\
\text { use them" EIPI } \\
\mathrm{O} \text { 'I think there's a separation between where the } \\
\text { money for the drugs comes from and the fact that } \\
\text { you're getting them for free. You don't always make } \\
\text { the link between the fact that they have to be paid } \\
\text { for by someone, somehow” SPI } \\
\mathrm{P} \text { “In Wales we're not putting our hands in our } \\
\text { pockets and paying for that prescription so we don't } \\
\text { take as much ownership because we're not wasting } \\
\text { our money” AP5 } \\
\mathrm{Q} \text { “What we actually do at the moment is we just } \\
\text { keep piling more medicines on, oh here's another one, } \\
\text { here's another... And that creates waste” AP3 } \\
\mathrm{R} \text { “There must be enormous amounts of stockpiling } \\
\text { because people keep going for their repeat } \\
\text { prescriptions because it's free the doctor signs it off } \\
\text { and it keeps coming” SP6 }\end{array}$ \\
\hline
\end{tabular}


perceived worth by the health care professional, which could either improve or undermine their trust in the health care system, depending on whether they considered they were getting good value for money (Table 3 , quotes $\mathrm{K}$ to $\mathrm{M}$ )

However, participants generally believed that prescribers had the expertise and the best intentions to prescribe the most appropriate medicine for them, and so ultimately participants felt it was important to trust their decision in what they have chosen to prescribe (Table 3, quote B). Participants across all groups felt that the cost had less of an impact on their decision to take a medication compared to the advice given to them by their health care provider. It was also acknowledged that cost would not have an influence on causes of wastage such as unintentional non-adherence or changes to regimens based on clinical needs (Table 3, quote $\mathrm{G}$ ).

\section{Theme 2: knowledge is power}

Across all groups, participants expressed a general lack of knowledge of how the NHS funds medications, how the taxpayer pays for medicines and what the standard prescription charge represents. Participants suggested that patients might like to be better informed about the funding and cost of their medicines (Table 3, quotes $\mathrm{K}$ to $\mathrm{M}$ ), which may lead them to feel more empowered to adjust their medication taking and ordering behaviors accordingly. In line with this, participants suggested that stating the cost followed by the words "funded by the UK taxpayer" on dispensing labels is not a clear enough statement on its own to convey the correct message and that either verbal or written explanation by the pharmacist would be necessary for them to fully understand its meaning.

Participants expressed an interest to learn more about their medicines generally, not just how much they cost, and this was suggested as a method by which adherence could be improved. The participants discussed promoting open communication channels between the patient and prescriber in an attempt to collaboratively make decisions and improve understanding (Table 3, quotes $\mathrm{H}$ and $\mathrm{J}$ ).

Participants felt that improving the knowledge of the medicines they are taking, and why, may help them to understand whether or not they need them and whether they can avoid wasting them. MURs were suggested as platform for this. However, concerns were raised, especially by participants in the working age adult group, that opening a discussion about cost with a patient might make the patient feel uncomfortable, guilty or lead them to believe that cost savings are being prioritized over the quality of their care, and thus undermine the integrity of the health care professional (Table 3, quote $\mathrm{M}$ ).
There was a general feeling across all groups that using the dispensing label would be an ineffective medium to communicate information about wastage (Table 3 , quote I), as when looking at medication boxes participants demonstrated that it is not always noticed, and often boxes are immediately discarded, let alone carefully read or considered. Participants argued that any effect of showing the price would be shortlived as people would become accustomed to seeing it.

\section{Theme 3: blame the system, not me!}

The idea of responsibility for wastage was a recurrent theme within discussions. Participants argued that this proposal puts the responsibility for wastage primarily on the patient, and there was feeling among all participant groups that patient behavior was not the sole cause of wastage, and the responsibility should be shared by the prescriber and health care system as well. For example, the practicalities of polypharmacy and the idea that adherence would always be poor where patients are prescribed a complicated, impracticable regimen were discussed. In addition, the concept of unavoidable waste was discussed, such as when a patient dies or the regimen changes such that medicines are no longer needed, for which the patient cannot be held responsible.

Participants indicated how easy it is to over-order medication through the current pharmacy repeat prescription service, facilitating stockpiling, and the perceived lack of monitoring of this process (Table 3, quotes $\mathrm{N}$ and $\mathrm{O}$ ). Some participants, particularly in the student and elderly groups, were unaware that even unused medicines returned to pharmacies have to be destroyed, and participants across all groups were concerned about the cost implications of this. It was also highlighted that people who are not paying for medication directly - such as Welsh residents or those meeting exemption criteria - might not be concerned about the financial impact of ordering them (Table 3, quotes P to R).

\section{Discussion \\ Main findings}

The general reaction to displaying the medication cost on the dispensing label was negative, with participants feeling that it alone would be insufficient to convey the correct meaning, may serve more to reprimand patients for needing medicines rather than encourage them to be used appropriately and would not be as effective in improving patient adherence as education and engagement. This is consistent with the sentiment of both the Royal Pharmaceutical Society's and Patient's Association public responses to this proposal, ${ }^{7,8}$ in which patient empowerment and understanding were 
considered equally relevant as cost in whether a patient takes their medication as prescribed.

\section{Strengths and limitations}

In terms of strengths, this study has provided insight into the general public's potential response to the proposal to include the cost on dispensing labels, which to our knowledge no previous research study has attempted. Our findings have provided key themes which can now be used inform a national questionnaire to the general public to provide more detailed scope of this topic.

The study explored members of the public's hypothetical response to the proposal, but this may not be reflective of how their actual response or behavior may be affected in practice. This can only be known through piloting the implementation of this proposal. Our study was relatively small, and participants were all living in the local area of Cardiff in Wales. Participants recruited for the working-age adult group were all university staff members, and thus all educated to degree level, and so may their views may not be representative of the general population. Similarly, a higher proportion of female participants were included in our focus groups, which may have affected results. Aside from these, individual characteristics for participants were not identified as part of the recruitment process. The participant characteristics were aspirational; therefore, we cannot say for certain if the collective group of participants was indeed diverse as intended. However, it is apparent from the data that a diverse range of experiences and opinions was demonstrable across the participants, providing rich data.

\section{Practice implications}

Concerns have been raised ${ }^{3-5,7,8}$ that knowing the cost of medicines may put some patients off taking them as prescribed, either due to them feeling the medicines were too costly to be justified, or too cheap to be considered effective. Consistent with the literature, our findings showed that the latter was indeed a concern, especially in elderly populations, who believed that cost was an indicator of effectiveness. This is a common misconception among the general public, as many of the most clinically effective medicines are those that are long established in the market and so considerably cheaper. This finding indicates that the proposal to display only the price of medicines costing $£ 20$ and over might be sensible, as patients would not know if their medicine was particularly inexpensive and this would not affect their perception of its clinical efficacy.

However, participants felt that if their medicines were deemed to be necessary, knowing the cost of their medicines would not affect whether they ordered or took them as prescribed. It follows then that more could be done to help patients understand which of their medicines are indeed necessary, and which could be used less, on an ad hoc basis, or even purchased instead of prescribed. Similarly, the prescribing of medicines considered superfluous could be avoided altogether. In England, some clinical commissioning groups have introduced restrictions on prescribing of medicines which can be purchased over the counter ${ }^{14}$ and the Choose Well national initiative in Wales encourages patients to access the appropriate service based on their ailment, avoiding unnecessary GP appointments and prescribing. ${ }^{15}$

\section{Patient engagement}

Participants' suggestion to increase outreach to patients by GPs and pharmacists on the subject of cost and wastage is consistent with the literature that the most effective method to increase adherence is through patient-centered models that increase patient understanding and involvement in decisions surrounding their health. ${ }^{1,16-20}$ However, our findings suggest that engaging with patients about the cost of their treatment could be a delicate matter that, if handled inappropriately, might cause patients to believe their care is being compromised to save costs, which would undermine confidence or trust in the health care professional. Any discussions on this subject would therefore need to be conducted sensitively, possibly with the provision of adequate staff training in place.

Our results indicate that, in order for this proposal to be safe, preventative action should be taken by health care professionals to reduce the risk of misunderstanding or patients being deterred from taking medicines. Participants suggested the provision of written information, such as a leaflet, should be provided alongside dispensed medicines to educate patients about the cost and what it means. This could also be used to explain funding of medicines in the NHS, a topic on which participants indicated they lacked knowledge. However, written information may be insufficient as there is no guarantee that the patient reads and understands what is provided, and there is evidence that a combination of written information and verbal counseling is more effective in improving patients' understanding of their medicines. ${ }^{16,21}$

However, available pharmacist time is a concern, and in spending time with patients explaining cost, the time spent counseling on the medication itself may be reduced. ${ }^{10}$ Alternative patient-facing methods, perhaps involving a GP practice-based pharmacist or increasing the scope of pharmacy-based MURs to include raising awareness of cost, might instead be worth further investigation. 


\section{Improving the system}

Many participants believed that the health care community itself could reduce medicines wastage by reviewing policies on polypharmacy, prescribing quantities, repeat prescriptions and the fate of medications returned to the pharmacy. In 2007, a UK study of returned medicines found that one-quarter of unused medication boxes returned to pharmacies and GP surgeries would be suitable for reuse, ${ }^{22}$ and our findings indicate that the public might be amenable to such initiatives. A smaller UK study in 2005 found that after a change in regimen, the second most common reason for returned medication was a clear out of accumulated medicines in the home, caused in part by over-ordering or supply of prescription items. ${ }^{23}$ These studies also found that a large proportion of returned items were due to potentially predictable causes and suggested that ensuring appropriate supply quantities might help to reduce the number of wasted medicines. Similarly, regular updating of the repeat ordering slip and deletion of inappropriate or unnecessary items could avoid excessive reordering and stockpiling behavior. ${ }^{24} \mathrm{An}$ improvement in these areas may be demonstrated in the near future with the increasing emergent roles of pharmacists working in GP practices to optimize prescribing, who can also play a role in promoting cost-conscious and efficient medicines usage by patients.

\section{Conclusion}

While a need to improve general awareness of cost and NHS funding of medicines among patient groups has been identified, results indicate that this information alone will not encourage a significant change in behavior. Further support to accompany this proposal as a practice change is necessary to avoid any patient misunderstanding and negative effects associated with feeling undervalued or guilty about the cost of their medication. Results instead indicate it would be more effective to treat the causes of wastage such as poor adherence and inappropriate prescribing and to engage effectively with patients about their medicines to help them to understand how to use them appropriately.

\section{Acknowledgments}

We are indebted to Steve Simmonds of the National Patient Association and Raj Aggarwal of Central Pharmacy, Cardiff, for proposing this research and providing site access and logistical support.

\section{Disclosure}

The authors certify that they have no affiliations with or involvement in any organization or entity with any financial interest or nonfinancial interest in the subject matter or materials discussed in this manuscript. The authors report no conflicts of interest in this work.

\section{References}

1. British Medical Association. A Vote for Health: BMA Manifesto. 2017. Available from: https://www.bma.org.uk/collective-voice/influence/ nhs-breaking-point/overview. Accessed July 4, 2017.

2. White K. UK interventions to control medicines wastage: a critical review. Int J Pharm Pract. 2010;18(3):131-140.

3. Trueman P, Taylor DG, Lowson K, et al. Evaluation of the Scale, Causes and Costs of Waste Medicines. Report of DH Funded National Project. York, London: York Health Economics Consortium and the School of Pharmacy, University of London; 2010. Available from: https://core. ac.uk/download/pdf/111804.pdf. Accessed July 4, 2017.

4. Department of Health Medicines Pharmacy and Industry Group. Making Best Use of Medicines. 2011. Available from: https://www.gov.uk/ government/uploads/system/uploads/attachment_data/file/216705/ dh_129216.pdf. Accessed July 4, 2017.

5. Steering Group on Improving the Use of Medicines (For Better Outcomes and Reduced Waste). Improving the Use of Medicines for Better Outcomes and Reduced Waste - An Action Plan. 2012. Available from: https://www.gov.uk/government/uploads/system/uploads/attachment_ data/file/212837/Improving-the-use-of-medicines-for-better-outcomesand-reduced-waste-An-action-plan.pdf. Accessed July 4, 2017.

6. Campbell D [webpage on the Internet]. Price to be written on NHSprescribed medicine costing more that $£ 20$. The Guardian. 2015. Available from: http://www.theguardian.com/society/2015/jul/01/nhsprescriptions-drugs-health-cost-waste-price. Accessed July 4, 2017.

7. Royal Pharmaceutical Society. Amendments to the Human Medicines Regulations 2012: 'Hub and Spoke' Dispensing, Prices of Medicines on Dispensing Labels, Labelling Requirements and Pharmacists' Exemption. Royal Pharmaceutical Society Response. 2016. Available from: https://www.rpharms.com/Portals/0/Documents/Old\%20consultations/ consdoc160520.pdf. Accessed July 4, 2017.

8. The Patients Association. Pharmacy Dispensing Models and Displaying Prices on Medicines, Consultation Response. 2016. Available from: http://www.patients-association.org.uk/wp-content/uploads/2016/05/ pharmacy-dispensing-models-and-displaying-prices-on-medicinesconsultation-final-2.pdf. Accessed July 4, 2017.

9. General Pharmaceutical Council. Response to the DH Consultation on Amendments to the Human Medicines Regulations 2012: 'Hub and Spoke' Dispensing, Prices of Medicines on Dispensing Labels, Labelling Requirements and Pharmacists' Exemption. 2016. Available from: https://www.pharmacyregulation.org/sites/default/files/ gphc_response_to_dh_consultation_on_pharmacy_dispensing_models_and_displaying_prices_on_medicines.pdf. Accessed July 4, 2017.

10. Wilcock M. It's not just about the money, money, money. Drug Ther Bull. 2015;53:85.

11. Freeman T. 'Best practice' in focus group research: making sense of different views. $J$ Adv Nurs. 2006;56:491-497.

12. Braun V, Clarke V. Using thematic analysis in psychology. Qual Res Psychol. 2006;3:77-101.

13. Lincoln YS, Guba EG. Naturalistic Inquiry. Newbury Park, CA: SAGE 1985.

14. Lacobucci G. Doctors call for national rules on OTC prescribing. $\mathrm{Br}$ Med J. 2017;356:j1442.

15. Wales NHS [homepage on the Internet]. Choose Well. 2011. Available from: http://www.choosewellwales.org.uk/home. Accessed July 4, 2017.

16. Haynes RB, Ackloo E, Sahota N, et al. Interventions for enhancing medication adherence. Cochrane Database Syst Rev. 2008;(2): CD000011.

17. Haynes RB, McKibbon AK, Kanani R. Systematic review of randomised trials of interventions to assist patients to follow prescriptions for medications. Lancet. 1996;348(9024):383-386.

18. McDonald HP, Garg AX, Haynes RB. Interventions to enhance patient adherence to medication prescriptions scientific review. JAMA. 2002;288(22):2868-2879. 
19. National Institute for Health and Care Excellence [webpage on the Internet]. Medicines Adherence: Involving Patients in Decisions about Prescribed Medicines and Supporting Adherence. 2009. Available from: http://www. nice.org.uk/guidance/cg76/chapter/introduction. Accessed July 4, 2017.

20. Bolan D, Chummun H. How patient beliefs affect adherence to prescribed medication regimens. Br J Nurs. 2013;22(5):270-276.

21. Curtis LM, Mullen R, RussellA, etal.An efficacy trial of an electronic health record-based strategy to inform patients on safe medication use: The role of written and spoken communication. Patient Educ Couns. 2016;99 (9): $1489-1495$.
22. Mackridge AJ, Marriott JF. Returned medicines: waste or a wasted opportunity? J Public Health (Oxf). 2007;29(3):258-262.

23. Langley C, Marriott J, Mackridge A, Daniszewski R. An analysis of returned medicines in primary care. Int J Clin Pharm. 2005;27(4): 296-299.

24. All Wales Medicines Strategy Group. All Wales Review and Guidance for Prescribing Intervals. 2013. Available from: http://www.awmsg. org/docs/awmsg/medman/All\%20Wales\%20Review\%20and\%20 Guidance\%20for\%20Prescribing\%20Intervals.pdf. Accessed July 4, 2017.

\section{Publish your work in this journal}

Integrated Pharmacy Research and Practice is an international, peer-reviewed, open access, online journal, publishing original research, reports, reviews and commentaries on all areas of academic and professional pharmacy practice. This journal aims to represent the academic output of pharmacists and pharmacy practice with particular focus on integrated care. All papers are carefully
Submit your manuscript here: http://www.dovepress.com/integrated-pharmacy-research-and-practice-journal peer reviewed to ensure the highest standards as well as ensuring that we are informing and stimulating pharmaceutical professionals. The manuscript management system is completely online and includes a very quick and fair peer-review system, which is all easy to use. Visit http://www.dovepress.com/ testimonials.php to read real quotes from published authors. 